\title{
EVALUATING THE INTERNAL AND EXTERNAL USABILITY ATTRIBUTES OF E-LEARNING WEBSITES IN SAUDi ARABIA
}

\author{
Khalid Al-Omar \\ Department of Information Systems, King Abdulaziz University, Jeddah, Kingdom of \\ Saudi Arabia
}

\begin{abstract}
Web usability is important for users who depend on the websites they use, such as online distance education students. Accordingly, universities and educational websites need to determine the types of usability problems that occur on their websites. However, far too little attention has been paid to providing detailed information regarding the types of specific usability problems that occur on e-learning websites in general and on those in the Kingdom of Saudi Arabia (KSA) in particular. The aim of this paper was to study and analyse the internal and external usability attributes of university websites that offer distance education courses in Saudi Arabia. Twelve universities in Saudi Arabia were considered-11 governmentaffiliated universities and one private university. The analysis of the data indicates the level of usability of distance education websites. Results reveal that in Saudi Arabia, distance education websites are reliable but violate basic usability guidelines. Furthermore, Saudi e-learning websites need to focus on the utility of their home page search engines, provide more advanced search functionality, and provide sitemaps linked to every page on the websites.
\end{abstract}

\section{KEYWORDS}

University websites, usability, credibility, e-learning, website design, Saudi Arabia, distance education

\section{INTRODUCTION}

Usability is an essential factor in measuring the quality of websites. It is one of the most important characteristics of any website, because if a website is not usable, no one will use it. Usability can increase users' comfort while interacting with the website and registering their personal information, which leads to user loyalty [1]. Moreover, searching for information on websites is challenging when usability guidelines are violated. ISO 9241-11 defines usability as 'the extent to which a product can be used by specified users to achieve specified goals with effectiveness, efficiency, and satisfaction in a specified context of use' [2].

Usability becomes even more vital in critical systems and in systems used by people who cannot visit the associated institution and depend mainly on the website, such as online distance education students. To draw students to their online distance education programmes, universities should be certain that their websites are usable. Therefore, e-learning and distance education websites at universities require high usability.

The remainder of the paper is organized as follows: First, an overview of usability evaluation is presented in Section 2, and a brief description of distance education in Saudi Arabia is provided in Section 3. Section 4 contains a brief description of relevant previous studies and a literature review, while in Section 5 the objectives of this work are presented. In Section 6, the methodology used is presented, and the automated website evaluation tools and results appear in Section 7. In Section 8, a website evaluation using a heuristic evaluation method is provided, with a discussion of these results in Section 9. Finally, conclusions and future work are discussed in Section 10. 


\section{USABILITY EVALUATION}

Various types of evaluation methods exist to examine usability. These methods are classified into three categories based on how the usability problems are identified:

- Tool-based evaluation methods include methods that involve software in the process of identifying usability problems. Common usability tools related to this category are Qualidator, Website Grader, WebPage Analyzer, and Search Engine Optimization (SEO) software.

- User evaluation methods include methods that involve users in the process of identifying usability problems. Common examples for this category are low fidelity prototypes and involving users in focus groups or controlled laboratory sessions to provide usability feedback [3-5].

- Expert evaluation methods include methods that involve an expert or a group of experts in the process of identifying usability problems. Common methods related to this category include heuristic evaluations $[1,6,7]$ and cognitive walkthroughs $[8,9]$.

\section{A Brief note about Distance Education in Saudi Arabia}

The number of universities in Saudi Arabia has increased in recent years. According to the Saudi Ministry of Higher Education, there are 36 universities in Saudi Arabia-25 government universities, 10 private universities, and one university focusing exclusively on graduate education and research, namely King Abdullah University of Science and Technology (KAUST). Of the 36 universities, only 11 government universities have been authorized by the Ministry of Higher Education to offer distance education courses ranging from bachelors' to masters' degrees, while only one private university (the Arab Open University) has been accredited by the Ministry of Higher Education. In this study, all 12 accredited universities that offer distance education were considered, evaluated, and analysed (Table 1).

Table 1: Year of Establishment of e-Learning and Distance Education Deanships at Universities in Saudi Arabia

\begin{tabular}{|c|l|l|l|}
\hline \multirow{2}{*}{ No } & \multirow{2}{*}{ University } & \multicolumn{2}{l|}{ Year of Establishment } \\
\cline { 2 - 4 } & & Gregorian & Hijri \\
\hline 1 & King Abdulaziz University (KAU) & 2002 & 1423 \\
\hline 2 & Islamic University in Madinah (IU) & 1961 & 1381 \\
\hline 3 & Al-Imam Mohammed Ibn Saud Islamic University (IMAMU) & 2007 & 1428 \\
\hline 4 & King Faisal University (KFU) & 2009 & 1430 \\
\hline 5 & Taibah University (TAIBAHU) & 2005 & 1426 \\
\hline 6 & Taif University (TU) & 2011 & 1432 \\
\hline 7 & Jazan University (JAZANU) & 2009 & 1430 \\
\hline 8 & Aljouf University (JU) & 2007 & 1428 \\
\hline 9 & Najran University (NU) & 2011 & 1432 \\
\hline 10 & University of Dammam (UD) & 2010 & 1430 \\
\hline 11 & Saudi Electronic University (SEU) & 2011 & 1432 \\
\hline 12 & Arab Open University (ARABOU) & 2002 & 1423 \\
\hline
\end{tabular}

Table 2 shows the number of male and female e-learning students enrolled in each university.

Table 2: Number of Online Distance Education Students in Saudi Arabia in 2014 


\begin{tabular}{|c|l|l|l|l|}
\hline No & University & Male & Female & Total \\
\hline 1 & KAU & 1,959 & 1,909 & 3,868 \\
\hline 2 & IU & 700 & 0 & 700 \\
\hline 3 & IMAMU & 5,156 & 3,733 & 8,889 \\
\hline 4 & KFU & 5,911 & 6,901 & 1,2812 \\
\hline 5 & TAIBAHU & 1,530 & 1,713 & 3,243 \\
\hline 6 & TU & 2,014 & 1,041 & 3,055 \\
\hline 7 & JAZANU & 876 & 810 & 1,686 \\
\hline 8 & JU & 199 & 66 & 265 \\
\hline 9 & NU & 1,005 & 977 & 1,982 \\
\hline 10 & UD & 957 & 1,241 & 2,198 \\
\hline 11 & SEU & 4,490 & 2,771 & 7,261 \\
\hline 12 & ARABOU & 1,914 & 2,340 & 4,254 \\
\hline
\end{tabular}

\section{LITERATURE REVIEW}

Evaluations of the usability of websites have been the subject of numerous research projects, with researchers focusing on topics such as e-learning (e.g., [10, 11]), e-government (e.g., [12, 13]), ecommerce (e.g., [14-18]), mobile website interfaces (e.g., [19, 20]), m-commerce (e.g., [21, 22]), and virtual and augmented reality (e.g., $[23,24])$.

However, few studies have evaluated the usability of e-learning websites by using automated tools. Alexander et al. [25] evaluated the usability and accessibility of three UK e-government websites and investigated whether these two characteristics are related using two automated usability evaluation tools, namely UsableNet LIFT and WatchFire Bobby, which enabled them to perform heuristic and walkthrough evaluations. They found that UK e-government websites showed high compliance with Web Content Accessibility Guidelines (WCAG) and a relatively low usability rating. Furthermore, Sukhpuneet et al. [26] used two automated tools, namely Site Analyser and Qualidator, to evaluate Punjabi universities and rank them according to specific evaluation criteria. They highlighted several underdeveloped areas on which website designers could focus. Ivory et al. [27] used three usability tools, namely W3C HTML, UsableNet LIFT, and WatchFire Bobby, and found that the tools helped designers to identify a larger number of usability problems. Moreover, Oliha et al. [28] evaluated the usability of the websites of two Nigerian polytechnics using HTML Toolbox and a Web Page Analyzer. Their study revealed that the overall usability level was acceptable but that some weaknesses existed in the design phase and interfaces. Junaini et al. [29] evaluated websites in three African countries by using the WebQual tool. The tool identified the HTML elements in hand-coded pages and presented the highest number of accessibility problems. Finally, Mustafa et al. [30] used HTML Toolbox and Web Page Analyzer to evaluate nine websites of Jordanian universities. Their results showed that the overall usability levels of the websites studied were acceptable.

Similarly, few studies have evaluated the usability of e-learning websites by using the heuristic evaluation method, and many of the existing studies adapted Nielsen's heuristics. For example, Albion [31] proposed a set of heuristics customized for the content of educational multimedia, and Schwier and Misanchunk presented a preliminary set of usability criteria that capture the features of e-learning systems [32]. Further, a study conducted by Reeves et al. [33] and based on Nielsen's heuristics expanded the original heuristics to include instructional design heuristics, while Mehlenbacher et al. [34] proposed a conceptual framework for the design and evaluation of all instructional situations. Squires and Preece [35] modified Nielsen's heuristics by considering socio-constructivism tenets. 


\section{OBJECTIVES}

The main objective of this study was to improve the usability of Saudi e-learning websites by examining the usability of e-learning and distance education deanship websites at universities in Saudi Arabia. In addition, the aim was to compare the online distance education websites of universities in Saudi Arabia and then offer suggestions for the design of an ideal online distance education website for a university to increase the site's usability.

\section{Methodology}

The human usability evaluation (conducted by users and experts) assessed the external attributes of the websites rather than their internal attributes (such as webpage download time). External attributes depend on the website and its usage, while internal attributes depend on how the website has been designed and developed [36]. It is important to examine both sets of attributes when evaluating usability. Thus, in this study, two website evaluation methods were used to obtain quality usability data. Automated tools were used to evaluate internal attributes, whereas heuristic evaluation was used to assess external attributes.

\section{Website Evaluation Using Automated Tools}

Automated tools were used to assess the internal attributes related to the usability of the elearning websites of Saudi universities. The numerous tools available have different usability attributes. In this study, three automated evaluation tools were chosen to analyse various usability factors such as performance, load time, navigation, mobile friendliness, and user satisfaction, as well as aspects such as SEO, accessibility, and security that contribute to user satisfaction. The website evaluation tools were

- Web Page Analyzer 0.98, a free tool for website optimization used to measure website performance and webpage speed to improve a website's performance;

- Qualidator, a free online tool that measures website performance, accessibility, SEO, and usability; and

- Website Grader, a free online tool that grades websites in terms of website performance, mobile friendliness, SEO, and security.

Table 3 shows the criteria used by each tool, specifically performance, accessibility, mobile friendliness, SEO, usability, and page analysis.

Table 3: Automated Website Evaluation Tools

\begin{tabular}{|l|c|c|c|}
\hline Criteria & Web Page Analyzer & Qualidator & Website Grader \\
\hline Performance & $\checkmark$ & $\checkmark$ & $\checkmark$ \\
\hline Accessibility & & $\checkmark$ & \\
\hline Mobile friendly & & & $\checkmark$ \\
\hline SEO & & $\checkmark$ & $\checkmark$ \\
\hline Security & & $\checkmark$ & \\
\hline Usability & & & \\
\hline Page analysis & $\checkmark$ & & \\
\hline
\end{tabular}

\subsection{Results Derived USINg Automated ToOls}

\subsubsection{Results Derived Using Web Page Analyzer}

Website download speed and the size of webpages influence the usability of any website. The data obtained using this tool represent the extent and level of website download speeds and the 
sizes of the webpages of the university websites under study. The total size of each website, the total size of the images on the website, the size of images as percentages of the total website sizes, and the download times were collected (see Table 4).

Table 4: Classification of Websites by Webpage Size and Download Speed

\begin{tabular}{|l|l|l|l|l|}
\hline $\begin{array}{l}\text { Name of } \\
\text { university }\end{array}$ & $\begin{array}{l}\text { Total size } \\
\text { of website }\end{array}$ & $\begin{array}{l}\text { Total size of } \\
\text { images }\end{array}$ & $\begin{array}{l}\text { Percentage } \\
\text { of images in } \\
\text { total size (\%) }\end{array}$ & $\begin{array}{l}\text { Download time } \\
\text { via 56K } \\
\text { connection (s) }\end{array}$ \\
\hline KAU & $1,885,781$ & 930,851 & 55 & 393.63 \\
\hline IU & $3,013,113$ & 451,273 & 98 & 949.76 \\
\hline IMAMU & 284,501 & 61,956 & 6 & 61.10 \\
\hline KFU & $1,017,485$ & 734,151 & 19 & 212.18 \\
\hline TAIBAHU & 974,124 & 789,597 & 74 & 212.74 \\
\hline TU & $2,155,286$ & $1,250,190$ & 44 & 441.35 \\
\hline JAZANU & $3,126,833$ & 458,363 & 99 & 969.56 \\
\hline JU & $2,461,388$ & $2,273,857$ & 72 & 514.35 \\
\hline NU & 457,998 & 448,225 & 11 & 93.88 \\
\hline UD & $2,528,954$ & $2,039,003$ & 84 & 525.42 \\
\hline SEU & 629 & 0 & 0 & 0.53 \\
\hline ARABOU & 633 & 0 & 0 & 0.53 \\
\hline
\end{tabular}

Web Page Analyzer's Speed Report recorded connection rates ranging from 1.44 Mbps to 14.4 Kbps. According to the usability guidelines [37], the optimal download time for a home page is 10 seconds. Thus, to improve download speed, the suggested size for home pages is $45 \mathrm{~kb}$ to 55 $\mathrm{kb}$. Table 4 shows that only two universities fell in the $<10$ seconds category, and only one university under the $>100$ seconds category. The remainder fell under the $>200$ seconds category. The websites contained numerous images, which constituted approximately $70-98 \%$ of the overall website sizes.

\subsubsection{Results Derived Using Qualidator}

Qualidator measurements involved key usability, accessibility, SEO, and overall usability (see Table 5). TAIBAHU's website could not be tested, as the server returned an error message that indicated that the operation had timed out. IMAMU obtained the highest usability score $(82.5 \%)$, while the highest accessibility scores were recorded for UD (81.7\%), JU (80.8\%), and NU $(80.6 \%)$. Both JU and IU scored the highest in terms of SEO (79.6\%). Overall, JU attained the highest score (78.5\%), followed by NU (77.3\%).

Table 5: Results of Qualidator Tool

\begin{tabular}{|l|l|l|l|l|}
\hline $\begin{array}{c}\text { University } \\
\text { website }\end{array}$ & $\begin{array}{c}\text { Usability } \\
(\boldsymbol{\%})\end{array}$ & $\begin{array}{c}\text { Accessibility } \\
(\boldsymbol{\%})\end{array}$ & SEO (\%) & $\begin{array}{c}\text { Overall } \\
(\boldsymbol{\%})\end{array}$ \\
\hline KAU & 68.6 & 67.2 & 68.1 & 72.8 \\
\hline IU & 76.5 & 76.3 & 79.9 & 75.7 \\
\hline IMAMU & 82.5 & 74.4 & 76.6 & 75.3 \\
\hline KFU & 72.8 & 69.0 & 61.4 & 70 \\
\hline TU & 66.5 & 65.6 & 67.3 & 66.2 \\
\hline JAZANU & 68.9 & 65.3 & 65.3 & 67.7 \\
\hline JU & 77.9 & 80.8 & 79.6 & 78.5 \\
\hline NU & 75.9 & 80.6 & 75.2 & 77.3 \\
\hline UD & 78.3 & 81.7 & 70.4 & 76.4 \\
\hline SEU & 77.7 & 78.5 & 68.3 & 75.3 \\
\hline ARABOU & 66.7 & 65.8 & 71.9 & 66.3 \\
\hline
\end{tabular}




\subsubsection{Results of Website Grader}

Website Grader measured key performance, mobile friendliness, SEO, security, and overall performance (see Table 6). TAIBAHU's website could not be tested due to a time-out error. UD (80/100) and KFU (79/100) achieved the highest overall scores, while TU, JAZANU, SEU, and ARABOU scored less than 50/100. For mobile friendliness, JAZANU, JU, NU, ARABOU scored zero, whereas the remaining universities scored full marks. In terms of performance, seven universities scored less than 15/30, and UD (30/30) and SE (26/30) attained the highest scores.

Table 6: Results of Website Grader Tool

\begin{tabular}{|l|l|l|l|l|l|}
\hline University & Performance & Mobile & SEO & Security & Overall \\
\hline KAU & $14 / 30$ & $30 / 30$ & $15 / 30$ & $10 / 10$ & $69 / 100$ \\
\hline IU & $14 / 30$ & $30 / 30$ & $15 / 30$ & $10 / 10$ & $69 / 100$ \\
\hline IMAMU & $14 / 30$ & $30 / 30$ & $20 / 30$ & $10 / 10$ & $74 / 100$ \\
\hline KFU & $14 / 30$ & $30 / 30$ & $25 / 30$ & $10 / 10$ & $79 / 100$ \\
\hline TU & $14 / 30$ & $0 / 30$ & $10 / 30$ & $10 / 10$ & $34 / 100$ \\
\hline JAZANU & $19 / 30$ & $0 / 30$ & $10 / 30$ & $0 / 10$ & $29 / 100$ \\
\hline JU & $20 / 30$ & $30 / 30$ & $15 / 30$ & $0 / 10$ & $65 / 100$ \\
\hline NU & $12 / 30$ & $30 / 30$ & $30 / 30$ & $0 / 10$ & $72 / 100$ \\
\hline UD & $30 / 30$ & $30 / 30$ & $10 / 30$ & $10 / 10$ & $80 / 100$ \\
\hline SEU & $26 / 30$ & $0 / 30$ & $10 / 30$ & $10 / 10$ & $46 / 100$ \\
\hline ARABOU & $13 / 30$ & $0 / 30$ & $10 / 30$ & $0 / 10$ & $23 / 100$ \\
\hline
\end{tabular}

\section{Website Evaluation Using Heuristic Evaluation}

As mentioned previously, heuristic evaluation is one of the various methods used to evaluate website usability. This method was employed in this study. Of the numerous heuristics evaluation guidelines available to assess usability attributes, Jakob Nielsen's 10 general principles for interaction design is one of the most widely used [1]. His heuristics consist of 10 items derived from problems found in usability studies of user interfaces. Another well-known standard with the aim of increasing usability is the ISO 9241-151 [38]. These heuristics provide guidance on the human-centred design of software Web-user interfaces. In terms of heuristics designed for evaluating e-learning websites, little appears in the literature, which is disproportionate to the importance of e-learning [39, 40]. In fact, most of the existing heuristics were formulated using Nielsen's 10 general principles, with some additions to reflect the needs of education websites. The developed heuristics include those formulated by Squires and Preece [35], Notess [41], Wong et al. [42], and Quinn et al. [40].

In this study, heuristic checklists were selected based on the ISO 9241-151 standard, Nielsen's 10 heuristics checklist, and Travis's checklist [43], and on those tailored to evaluate e-learning websites such as the guidelines created by Squires and Preece [35]. To evaluate the usability of a given website, the website must be checked by one or more experts using a predefined set of heuristic guidelines. For this study, self-evaluation was employed to assess usability by using heuristic guidelines.

The resulting heuristic checklist consisted of 181 questions covering nine components (see Table 7). 
Advanced Computing: An International Journal (ACIJ), Vol.8, No.3/4, July 2017

Table 7: Number of Heuristics Examined under Each Principle

\begin{tabular}{|l|l|c|}
\hline Component & Description & $\begin{array}{l}\text { Number of } \\
\text { heuristics }\end{array}$ \\
\hline Home page & How well a website supports users' tasks & 18 \\
\hline Task orientation & How well a website supports users' tasks & 27 \\
\hline Navigation & $\begin{array}{l}\text { Navigation system that aids users when } \\
\text { browsing the website }\end{array}$ & 26 \\
\hline Forms and data entry & Clear and easy-to-complete forms & 7 \\
\hline Trust and credibility & $\begin{array}{l}\text { Content that is precise and recent, with clear } \\
\text { information regarding the privacy policy }\end{array}$ & 22 \\
\hline $\begin{array}{l}\text { Writing and content } \\
\text { quality }\end{array}$ & Content must be written for the Web & 38 \\
\hline Design and consistency & $\begin{array}{l}\text { Visually appealing design with consistent } \\
\text { look and feel }\end{array}$ & 20 \\
\hline Search & $\begin{array}{l}\text { Effective search feature that enables users to } \\
\text { locate the required information easily }\end{array}$ & 12 \\
\hline $\begin{array}{l}\text { Help, feedback, and } \\
\text { error tolerance }\end{array}$ & $\begin{array}{l}\text { Effective mechanism to help users and } \\
\text { provide them with the required feedback }\end{array}$ & 11 \\
\hline
\end{tabular}

\subsection{Results of Heuristic Evaluation}

All the heuristic criteria had to be met for each proposed component to have a prefect usable website. Figure 1 shows the overall percentage of heuristics that were met for each usability component.

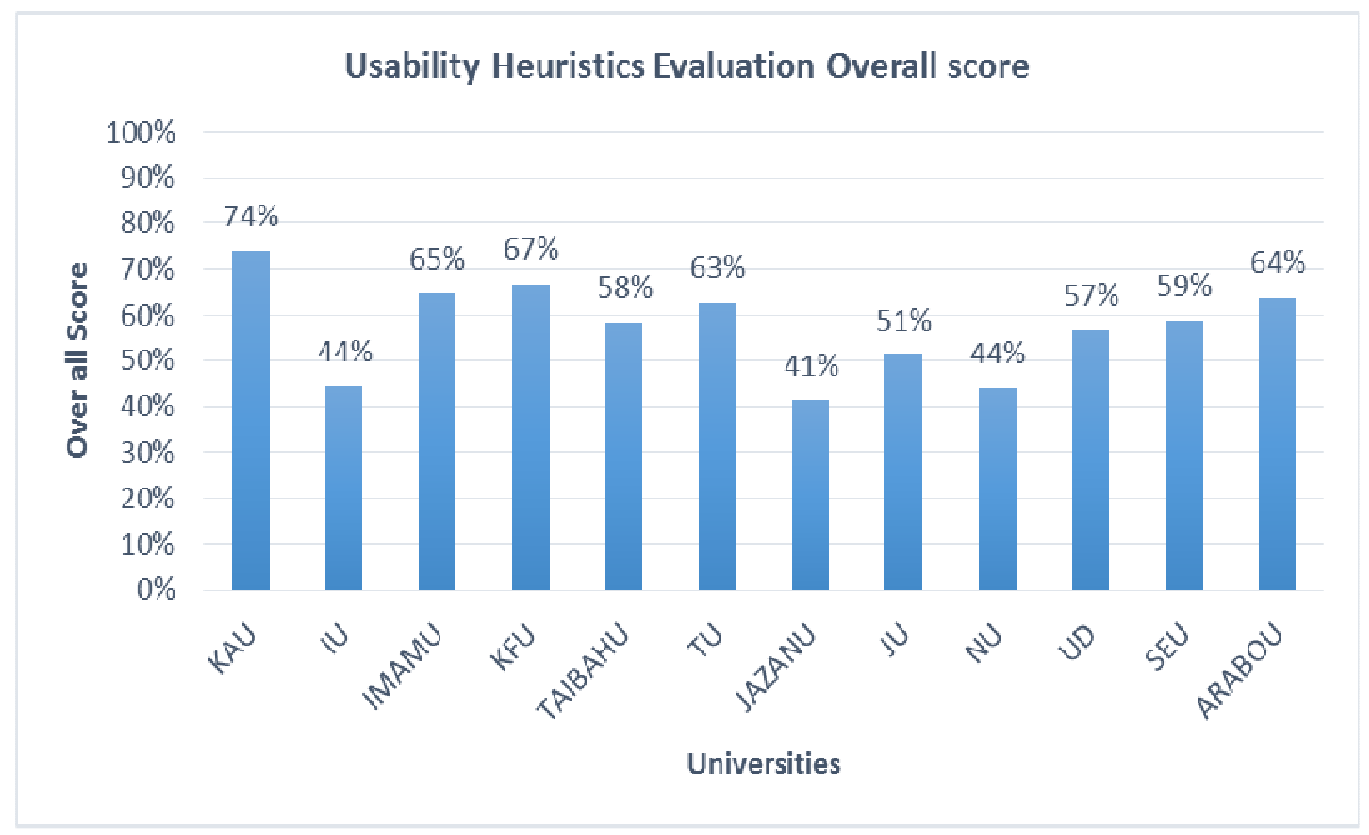

Figure 1: Usability Heuristics Evaluation Overall Score

Table 8 shows that the Saudi e-learning websites did not fully meet any of the nine proposed components. Additionally, all components scored less than $85 \%$, which might indicate a tendency towards a need to implement usability best practices. 
Table 8: Usability Evaluation Score Percentages for Each Principle

\begin{tabular}{|l|c|c|c|c|c|c|c|c|c|c|c|c|}
\hline & KAU & IU & $\begin{array}{c}\text { IMA- } \\
\text { MU }\end{array}$ & KFU & $\begin{array}{c}\text { TAIBA- } \\
\text { HU }\end{array}$ & TU & $\begin{array}{c}\text { JAZA- } \\
\text { NU }\end{array}$ & JU & NU & UD & SEU & $\begin{array}{c}\text { ARAB- } \\
\text { OU }\end{array}$ \\
\hline $\begin{array}{l}\text { Home } \\
\text { page }\end{array}$ & 83 & 58 & 47 & 75 & 36 & 67 & 19 & 56 & 31 & 75 & 69 & 67 \\
\hline $\begin{array}{l}\text { Task } \\
\text { orientation }\end{array}$ & 57 & 56 & 56 & 61 & 56 & 65 & 46 & 57 & 46 & 61 & 61 & 56 \\
\hline Navigation & 69 & 38 & 52 & 58 & 52 & 48 & 37 & 54 & 37 & 48 & 48 & 38 \\
\hline $\begin{array}{l}\text { Forms and } \\
\text { data entry }\end{array}$ & 64 & 50 & 50 & 43 & 43 & 57 & 50 & 79 & 50 & 57 & 43 & 71 \\
\hline $\begin{array}{l}\text { Trust and } \\
\text { credibility }\end{array}$ & 82 & 64 & 73 & 77 & 59 & 73 & 41 & 77 & 41 & 82 & 77 & 82 \\
\hline $\begin{array}{l}\text { Writing } \\
\text { and } \\
\text { content } \\
\text { quality }\end{array}$ & 80 & 82 & 77 & 68 & 77 & 73 & 77 & 66 & 77 & 68 & 68 & 68 \\
\hline $\begin{array}{l}\text { Page } \\
\text { layout and } \\
\text { visual } \\
\text { design }\end{array}$ & 84 & 53 & 64 & 66 & 55 & 62 & 51 & 74 & 51 & 66 & 64 & 59 \\
\hline Search & 55 & 0 & 73 & 70 & 63 & 50 & 0 & 0 & 13 & 0 & 0 & 70 \\
\hline $\begin{array}{l}\text { Help, } \\
\text { feedback, } \\
\text { and error } \\
\text { tolerance }\end{array}$ & 83 & 0 & 63 & 54 & 50 & 50 & 50 & 0 & 50 & 54 & 63 & 83 \\
\hline $\begin{array}{l}\text { Overall } \\
\text { score }\end{array}$ & 74 & 44 & 65 & 67 & 58 & 63 & 41 & 51 & 44 & 57 & 59 & 64 \\
\hline
\end{tabular}

Further, the average writing and content quality score across all 12 institutions was the highest at around $73 \%$ (see Table 9). This can be attributed to most of the evaluated websites fulfilling the heuristics of this component by, for example, displaying the most important items in a list at the top of the page; writing sentences in the active voice; avoiding cute, clever, or cryptic headings; using hypertext appropriately to structure content; defining acronyms and abbreviations on first use; and using words, phrases, and concepts familiar to the typical user.

Table 9: Usability Evaluation Average Score Percentages for Each Principle

\begin{tabular}{|l|c|}
\hline Component & Average score \\
\hline Home Page & $57 \%$ \\
\hline Task Orientation & $56 \%$ \\
\hline Navigation & $48 \%$ \\
\hline Forms \& Data Entry & $55 \%$ \\
\hline Trust \& Credibility & $69 \%$ \\
\hline Writing \& Content Quality & $73 \%$ \\
\hline Page Layout \& Visual Design & $63 \%$ \\
\hline Search & $33 \%$ \\
\hline Help, Feedback \& Error Tolerance & $50 \%$ \\
\hline Overall score & $57 \%$ \\
\hline
\end{tabular}

Search functionality scored the lowest average value, with 33\%, as nearly half the websites did not support search functionality, and most other websites lacked advanced search functionality. Moreover, the search scope was limited to certain content, and on some websites, the search results were not sorted or ranked by relevance. Furthermore, navigation scored the second lowest average score, with $44 \%$, because half the websites studied did not have site maps, and on the other half, the site maps did not link to every page. 
Similarly, the average score for the forms and data entry component was low, with a value of $55 \%$, due to a lack of concern about creating accessible and usable Web forms. Forms lacked clear distinction between required and optional fields, as well as completion guidelines, and some forms failed to provide appropriate feedback that allowed error correction.

In terms of the help, feedback, and error tolerance component, two e-learning websites did not provide an FAQ page or online help, and the results show that little consideration was given to creating accessible help systems. Problems included that the FAQ or online help sections did not provide step-by-step instructions to help users carry out the most important tasks, and most websites did not provide useful feedback when needed.

The average score for the task orientation component also was low at $56 \%$, with half the websites lacking critical paths and the remainder providing unclear critical paths with distractions on route. Furthermore, none of the websites allowed users to customize features, for example, by renaming objects or through actions in the interface.

The trust and credibility component achieved a reasonable score at $69 \%$. The websites studied fulfilled the related heuristics such as the content is up to date, the site contains third-party support, it is clear that there is a real organisation behind the site, the site avoids advertisements, and the site is free of typographical errors and spelling mistakes.

\section{DisCUSSION}

The analysis with the automated tools indicated that in terms of the design factor, only the SU and KAU websites scored higher than $50 \%$. The SEU, NU, KAU, and IU websites achieved the highest score $(61 \%)$ for the ease-of-use factor, with the rest scoring below $50 \%$. This indicates that half the websites contained usability problems. In contrast, most websites achieved a high score on reliability factors. The JU website scored the lowest for both the validity and expertise factors, followed by the NU website. Three university websites (those of KAU, KFU, and SEU) achieved full marks in the expertise area.

Moreover, the heuristic evaluation method showed that Saudi e-learning websites need to improve their home page search engines and provide more advanced search functionality. Additionally, websites must provide sitemaps that link to every page on their websites.

\section{CONClusion AND Future Work}

The main goal of the current study was to examine the internal and external usability attributes of university websites that offer distance education courses in Saudi Arabia. The results of this investigation show that university websites were reliable and well designed but violated basic accessibility and usability guidelines. In addition, Saudi e-learning websites need to improve their home page search engines, and provide advanced search functionality and fully functional sitemaps linked to every page on their websites.

University websites in Saudi Arabia should be required to be evaluated periodically using established criteria such as usability, accessibility, and credibility. This will help the universities improve their websites to meet users' needs. The current study should be repeated using the user evaluation method. 


\section{REFERENCES}

[1] J.Nielsen, "How to conduct a heuristic evaluation," retrieved November, vol. 10, 2001.

[2] T.Jokela, N. Iivari, J. Matero, and M. Karukka,"The standard of user-centered design and the standard definition of usability: analyzing ISO 13407 against ISO 9241-11," in Proceedings of the Latin American conference on Human-computer interaction, 2003, pp. 53-60.

[3] J.Brooke,"SUS-A quick and dirty usability scale," Usability evaluation in industry, vol. 189, pp. 4-7, 1996.

[4] G.Perlman, "Web-based user interface evaluation with questionnaires," Retrieved March, vol. 1, p. 2003, 2001.

[5] T. S. Tullis and J. N. Stetson, "A comparison of questionnaires for assessing website usability," in Usability Professional Association Conference, 2004, pp. 1-12.

[6] J. Nielsen and R. Molich,"Heuristic evaluation of user interfaces," in Proceedings of the SIGCHI conference on Human factors in computing systems, 1990, pp. 249-256.

[7] E. T. Hvannberg, E. L.-C. Law, and M. K. Lérusdóttir, "Heuristic evaluation: Comparing ways of finding and reporting usability problems," Interacting with computers, vol. 19, pp. 225-240, 2007.

[8] P. G. Polson, C. Lewis, J. Rieman, and C. Wharton,"Cognitive walkthroughs: a method for theory-based evaluation of user interfaces," International Journal of man-machine studies, vol. 36, pp. 741-773, 1992.

[9] M. H. Blackmon, P. G. Polson, M. Kitajima, and C. Lewis, "Cognitive walkthrough for the web," in Proceedings of the SIGCHI conference on human factors in computing systems, 2002, pp. 463-470.

[10] K. Orfanou, N. Tselios, and C. Katsanos,"Perceived usability evaluation of learning management systems: Empirical evaluation of the System Usability Scale," The International Review of Research in Open and Distributed Learning, vol. 16, 2015.

[11] M. Alshammari, R. Anane, and R. J. Hendley, "Design and Usability Evaluation of Adaptive elearning Systems Based on Learner Knowledge and Learning Style," in Human-Computer Interaction, 2015, pp. 584-591.

[12] Z. Huang and M. Benyoucef, "Usability and credibility of e-government websites," Government Information Quarterly, vol. 31, pp. 584-595, 2014.

[13] H. Gull and S. Z. Iqbal "Usability Evaluation of E-Government Websites in Saudi Arabia by Cognitive Walkthrough," Design Solutions for User-Centric Information Systems, p. 297, 2016.

[14] B. Fogg, J. Marshall, O. Laraki, A. Osipovich, C. Varma, N. Fang, et al.,"What makes Web sites credible?: a report on a large quantitative study," in Proceedings of the SIGCHI conference on Human factors in computing systems, 2001, pp. 61-68.

[15] C. N. Wathen and J. Burkell,"Believe It or Not: Factors Influencing Credibility on the Web," JOURNAL OF THE AMERICAN SOCIETY FOR INFORMATION SCIENCE AND TECHNOLOGY, vol. 53, pp. 134-144, 2002.

[16] F. Alsudani and M. Casey, "The effect of aesthetics on web credibility," in Proceedings of the 23rd British HCI Group Annual Conference on People and Computers: Celebrating People and Technology, 2009, pp. 512-519.

[17] L. Song, J. Lai, and J. Li, "Identifying Factors Affecting Individual Perceived Credibility on SNS," in Proceedings of the The 3rd Multidisciplinary International Social Networks Conference on SocialInformatics 2016, Data Science 2016, 2016, p. 2.

[18] J. F. George, G. Giordano, and P. A. Tilley, "Website credibility and deceiver credibility: Expanding Prominence-Interpretation Theory," Computers in Human Behavior, vol. 54, pp. 8393, 2016.

[19] A. S. Tsiaousis and G. M. Giaglis, "Mobile websites: usability evaluation and design," International Journal of Mobile Communications, vol. 12, pp. 29-55, 2014. 
[20] B. C. Zapata, J. L. Fernández-Alemán, A. Idri, and A. Toval, "Empirical studies on usability of mHealth apps: A systematic literature review," Journal of medical systems, vol. 39, pp. 1-19, 2015.

[21] A. Hussain, E. O. Mkpojiogu, F. A. A. Nifa, M. N. M. Nawi, and A. Hussain, "Usability evaluation techniques in mobile commerce applications: a systematic review," in AIP Conference Proceedings, 2016, p. 020049.

[22] A. Hussain, E. O. Mkpojiogu, and F. M. Kamal, "A Systematic Review on Usability Evaluation Methods for M-Commerce Apps," Journal of Telecommunication, Electronic and Computer Engineering (JTEC), vol. 8, pp. 29-34, 2016.

[23] P. Rane, H. Kim, J. L. Marcano, and J. L. Gabbard, "Virtual Road Signs: Augmented Reality Driving Aid for Novice Drivers," in Proceedings of the Human Factors and Ergonomics Society Annual Meeting, 2016, pp. 1750-1754.

[24] A. S. Merians, D. Jack, R. Boian, M. Tremaine, G. C. Burdea, S. V. Adamovich, et al., "Virtual reality-augmented rehabilitation for patients following stroke," Physical therapy, vol. 82, pp. 898-915, 2002.

[25] A. Rukshan and A. Baravalle, "Automated Usability Testing: Analysing Asia Web Sites," arXiv preprint arXiv:1212.1849, 2012.

[26] S. Kaur, K. Kaur, and P. Kaur, "Analysis of website usability evaluation methods," in Computing for Sustainable Global Development (INDIACom), 2016 3rd International Conference on, 2016, pp. 1043-1046.

[27] M. Y. Ivory and A. Chevalier, "A study of automated web site evaluation tools," University of Washington, Department of Computer Science2002, 2002.

[28] F. Oliha, "Web portal usability among Nigerian university students: A case study of University of Benin, Nigeria," Nigerian Journal of Technology, vol. 33, pp. 199-206, 2014.

[29] S. Junaini, "Navigation design and usability evaluation of the Malaysian public university websites," in Proceedings of the Second National Conference on Cognitive Science CSC, 2002, pp. 181-189.

[30] S. H. Mustafa and L. F. Al-Zoua'bi, "Usability of the academic websites of Jordan's universities an evaluation study," in Proceedings of the 9th International Arab Conference for Information Technology, 2008, pp. 31-40.

[31] P. Albion, "Heuristic evaluation of educational multimedia: from theory to practice," in Proceedings ASCILITE 1999: 16th Annual Conference of the Australasian Society for Computers in Learning in Tertiary Education: Responding to Diversity, 1999, pp. 9-15.

[32] R. Schwier and E. R. Misanchuk, Interactive multimedia instruction: Educational Technology, 1993.

[33] T. C. Reeves, L. Benson, D. Elliott, M. Grant, D. Holschuh, B. Kim, et al., "Usability and Instructional Design Heuristics for E-Learning Evaluation," 2002.

[34] B. Mehlenbacher, L. Bennett, T. Bird, M. Ivey, J. Lucas, J. Morton, et al., "Usable e-learning: A conceptual model for evaluation and design," in Proceedings of HCI International, 2005, p. 11 th.

[35] D. Squires and J. Preece, "Predicting quality in educational software: Evaluating for learning, usability and the synergy between them," Interacting with computers, vol. 11, pp. 467-483, 1999.

[36] G. Brajnik, "Automatic web usability evaluation: what needs to be done," in Proc. Human Factors and the Web, 6th Conference, 2000.

[37] J. Nielsen, "Designing web usability: the practice of simplicity New Riders Publishing," Indianapolis, Indiana, 2000.

[38] N. Bevan, "Guidelines and standards for web usability," in Proceedings of HCI International, 2005.

[39] M. A. Storey, B. Phillips, M. Maczewski, and M. Wang, "Evaluating the usability of Web-based learning tools," Educational Technology \& Society, vol. 5, pp. 91-100, 2002. 
Advanced Computing: An International Journal (ACIJ), Vol.8, No.3/4, July 2017

[40] C. Quinn, L. Alem, and J. Eklund, "A pragmatic evaluation methodology for an assessment of learning effectiveness in instructional systems," Human-Computer Interaction, vol. 2, pp. 55$56,1997$.

[41] M. Notess, "Usability, user experience, and learner experience," eLearn, vol. 2001, p. 3, 2001.

[42] S. Wong, T. Nguyen, E. Chang, and N. Jayaratna, "Usability metrics for e-learning," in On The Move to Meaningful Internet Systems 2003: OTM 2003 Workshops, 2003, pp. 235-252.

[43] D. Travis, "247 web usability guidelines," Retrieved January, vol. 4, p. 2012, 2009. 